\title{
LOS INVENTARIOS DE JOSÉ EMILIO PACHECO: UNA AJUSTADA CONCEPCIÓN POÉTICA
}

\author{
Asunción del Carmen Rangel López \\ Universidad de Guanajuato \\ dite23@gmail.com
}

\begin{abstract}
RESUMEN: El artículo recorre algunas reflexiones contenidas en los Inventarios de José Emilio Pacheco, las cuales permiten poner a trasluz su concepción poética; ahí se pone de manifiesto un ajustado pensamiento de índole teórica. Los Inventarios se aproximan al deber ser de la crónica literaria, pero dejan de pertenecer a ese género, se degeneran, para convertirse en una forma peculiar de crítica literaria que no es ni académica ni de divulgación. Los elementos discursivos de la crónica van menguando y en su aminoramiento dejan un rastro que permite reconocerlos como crónica, pero contaminada de otra cosa: verso, retrato, anécdota, chisme.
\end{abstract}

PALABRAS CLAVE: crónica, pensamiento literario, poética, literatura mexicana, poesía.

\section{INVENTARIOS OF JOSÉ EMILIO PACHECO: AN ADJUSTED POETIC CONCEPTION}

\begin{abstract}
The article goes through some ruminations contained in Inventarios of Jose Emilio Pacheco, which allow a through sight of his poetic conception; there is where an adjusted thought of a theoretical nature is revealed. The inventories -Inventarios- approximate to the duty of the literary chronicle, but they stop belonging to that genre, they degenerate to become a peculiar form of literary criticism that is neither academic nor of divulgation. The discursive elements of the chronicle wane and in their lessening they leave a trace that allows them to be recognized as chronicle, but contaminated of something else: verse, portrait, anecdote, gossip.
\end{abstract}

KEYWORDS: chronicle, literary thought, Mexican literature, poetry. 


\title{
LES INVENTAIRES DE JOSÉ EMILIO PACHECO: UNE FINE CONCEPTION POÉTIQUE
}

\begin{abstract}
RÉSUMÉ: L'article passe en revue quelques réflexions contenues dans les Inventaires de José Emilio Pacheco qui laissent transparaître sa conception poétique; c'est là qu'une fine pensée de nature théorique se manifeste. Les Inventaires se rapprochent du devoir être de la chronique littéraire, mais ils cessent alors d'appartenir à ce genre, ils dégénèrent, pour devenir une forme particulière de critique littéraire qui n'est ni académique ni de vulgarisation. Les éléments discursifs de la chronique diminuent et, en diminuant, ils laissent une trace qui leur permet d'être reconnus comme chronique, mais contaminée par une autre chose: vers, portrait, anecdote, potins.

MOTS CLÉS: chronique, pensée littéraire, poésie, littérature mexicaine, José Emilio Pacheco.
\end{abstract}

Recibido: 06/09/2018. Aceptado: 10/12/2018

\section{José Emilio, el ornitorrinco}

A propósito de las “maneras de definir lo que no se define”, es decir, la crónica contemporánea, Alicia S. Montes repasa alguna de las maneras en que varios escritores se han referido a eso que a la crítica y a la teoría literaria tanto les ha constado asir mediante un concepto:

[...] es importante -apunta Montes- dejar que el coro de voces que construyen el relato de su imposible tipificación revelen y velen con gesto perverso el vacío de su secreto: "una manera de ir a la calle, de dar testimonio directo” (Rodríguez Juliá, 2009); “borderline de la crítica de artes”, "laboratorio de ensayo del estilo” (Rotker, 1995); “escritura a la intemperie”, “caleidoscopio oscilante” (Lemebel, 2007); “ornitorrinco de la prosa” (Villoro, 2005); "género por demás camaleónico” (Reguillo, 2007); "la intensidad prosística, el humor, la fantasía y el desmadre” (Monsiváis, 1980); “escritura en tránsito”, “rara avis” (Falbo, 2007); "escritura transgenérica de la violencia” (Bencomo, 2007); "narrativa de la urgencia” (Poblete, 2007); “literatura en bermudas” (Ferreira dos Santos, 2007); “animalito raro" (Esquivada, 2007); "hija incestuosa de la historia y de la literatura, que existe desde mucho antes que el periodismo” (Ethel, 2008). (Montes 2014: 49, 50). 
Además de notar la suerte de bestiario -ornitorrinco, avis, animalito- que descuella en algunos de los atisbos de definición de los cronistas, es de destacar la tentación por la metáfora en la que no tienen empacho en caer. Ferreira dos Santos, por ejemplo, le pone unos pantalones cortos a la literatura, o Pedro Lemebel, sustantiva y adjetiva para lograr una imagen que describe con fortuna su manera de concebir la crónica contemporánea: "caleidoscopio oscilante”.

Del bestiario, empleado por Falbo, Esquivada y Villoro, quiero destacar la de este último. Decir que la crónica es "el ornitorrinco de la prosa" resulta profundamente sugerente si tenemos a la vista aquella definición de Alfonso Reyes sobre el ensayo literario: "El ensayo, género mixto, centauro de los géneros, responde a la variedad de la cultura moderna, más múltiple que armónica” (Reyes: 1980: 58). Será el propio Alfonso Reyes -quién sino él, un enamorado irredento del mundo grecolatino- quien nos da noticias de los mitos relacionados con el origen del centauro: "una raza híbrida de Centauros, entre hombres y caballos". (360). Al referirse a la familia olímpica, en el ensayo dedicado a la mitología griega, particularmente en la descripción de los Sátiros, apunta: "híbridos de hombre y bestia -lo que los acerca a los Centauros-" (500). La hibridez, en ese tenor, será el rasgo que compartan el género ensayo y el Centauro, pero es una mezcla, un híbrido, de dos elementos muy particulares: entre hombre y bestia, entre hombre y caballo. Cuando Villoro señala que la crónica es el "ornitorrinco de la prosa”, está poniendo en circulación la ya consagrada sentencia de Alfonso Reyes, pero la complejiza. Frente al Centauro, coloca el ornitorrinco; frente al ensayo, la prosa. La filiación con la sentencia de Reyes, es puesta en evidencia por el propio Juan Villoro en Safari accidental (2005). En la nota que sirve de prólogo al libro, apunta: "Si Alfonso Reyes juzgó que el ensayo es el centauro de los géneros, la crónica reclama un símbolo más complejo: el ornitorrinco de la prosa" (2005: 14).

El ornitorrinco no es una bestia mitológica, se trata de un animal que hasta hace pocos años desconcertó a los biólogos y taxónomos. Su constitución no es para menos: hocico en forma de pico pato, cola de castor y patas de nutria, todavía más, es venenoso y pone huevos. En el Manual de literatura para caníbales, Rafael Reig describe el encuentro de George Shaw, zoólogo inglés, con el animalejo extraño: 


\begin{abstract}
¿Un animal con piel de topo, patas de rana, cola de castor, pico e pato y además con dientes? En cuanto lo vio, Shaw se dio cuenta de que aquello solo podría ser un fraude. Arqueó la ceja, carraspeó y, tijeras en mano, se dispuso a descubrir las costuras disimuladas. A él no se le engañaba con tanta facilidad.

[...] Shaw no encontró rastros de costura ni indicio alguno de falsificación. Se quedó atónito. [...] ¿qué estaba ocurriendo? ¿qué era entonces aquello? (Reig 2006: 36).
\end{abstract}

La extrañeza que causó a los europeos el encuentro con el ornitorrinco, hacia 1797, alcanza a parecerse a la extrañeza que causa la crónica literaria; “[...] la crónica termina siendo algo así como un tipo de texto sobre el que se puede decir cualquier cosa sin temor a equivocarse” (Montes 2014: 11). De acuerdo con una investigación divulgada en la revista Nature en 2008 (lajornada.com), científicos de la Escuela de Medicina de Washington, publican datos que ponen en evidencia -científica, genética, por supuesto- que el ornitorrinco es mamífero, ave y reptil a la vez (ver bibliografía). En el contexto de la extrañeza que generó el estrambótico mamífero y la claridad científica que permitió describirlo con certeza muchos años después, encuentro profundamente afortunada la definición de Juan Villoro, y no sólo en lo relacionado con los ambiguos movimientos de la crónica, sino también por sus adeptos.

La complejidad del símbolo empleado por Villoro, en el parangón complejizado que entabla con la sentencia de Alfonso Reyes, también permite entrever otro tipo de resonancias y relaciones cuando se piensa en la obra de un escritor como José Emilio Pacheco.

Pacheco es, me permitiré decirlo, el ornitorrinco de su generación. Además, su obra periodística reclama una relación de extrañeza -como la de George Shaw frente al extraño mamífero-, frente a la obra narrativa o la escrita en verso.

El autor de Tarde o temprano nace en 1939. De acuerdo con los taxónomos o críticos de la historia literaria mexicana del siglo XX, Pacheco pertenece a la llamada Generación del Medio Siglo. En "La generación del Medio Siglo" (1998), Armando Pereira, apunta una serie de publicaciones y sucesos que marcan el contexto específico "del universo cultural de mediados de los años cincuenta" (Pereira 1998: 127, 128): El laberinto de la soledad de Octavio Paz en 1950 -año en que muere Xavier Villaurrutia-, Los sonetos de Carlos Pellicer y el estreno de El cuadrante de la soledad de José Revueltas, en el mismo año. Entre 1950 y 1955, aparecen también ¿Águila o sol? del ya aludido Paz, La x en la frente de Alfonso Reyes, Confabulario de Juan José Arreola y Pedro Páramo de Juan Rulfo. En 1951, además, se funda el Centro Mexicano de Escritores, 
[...] bajo la asesoría de Juan José Arreola y Juan Rulfo, acogió como becarios a muchos de los narradores de la Generación del Medio Siglo. Durante la década que va de fines de los cincuenta a fines de los sesenta, gozaron del apoyo del Centro: Jorge Ibargüengoitia, Vicente Leñero, Juan García Ponce, Fernando del Paso, Inés Arredondo, Carlos Monsiváis, Salvador Elizondo y José Emilio Pacheco (Pereira 1998: 129).

Los espacios culturales y de discusión comunes no fueron pocos. También coindicen en, por ejemplo, la Coordinación de Difusión General de la Universidad Nacional Autónoma de México, en la Dirección General de Publicaciones y en la Imprenta Universitaria; en las publicaciones periódicas: en la Revista de la Universidad, Cuadernos del Viento, La palabra y el hombre, México en la Cultura (del periódico Novedades) y La cultura en México (de la revista Siempre!). Pero no sólo eso, también compartían, como otrora la generación denominada Contemporáneos prefirió la poesía, el cultivo de un género literario en particular: la narrativa. Salvador Elizondo publica Farabeuf o la crónica de un instante (1965), El hipogeo secreto (1968); Juan Vicente Melo, La obediencia nocturna (1969); Sergio Pitol, El tañido de la flauta (1972); Juan García Ponce, La casa en la playa (1966); Inés Arredondo, Río subterráneo (1979); y José Emilio Pacheco, Morirás lejos (1967, 1977).

Pereira apunta algunos de los datos por los que fueron llamados "mafia literaria”. Esta idea comienza a forjarse:

[...] a partir de la constante e incisiva presencia de esos jóvenes y veleidosos escritores en los dos suplementos que dirigió Benítez en la década de los setenta. [...] Y si a eso agregamos su presencia, constante e incisiva también, en las demás publicaciones literarias, en los centros de cultura e, incluso, en las principales casas editoriales del momento -Fondo de Cultura Económica, Siglo XXI, Era, Joaquín Mortiz y la Universidad Veracruzana-, podría parecer que todo el ámbito cultural mexicano estaba dominado por una pequeña élite de muchachos intransigentes, pretenciosos y extranjerizantes que mangoneaban los gustos artísticos de un país [reproche análogo al que se le hacía a los Contemporáneos]. Existe incluso una acuciosa investigación (aún no publicada en México) de una escritora belga. Kristine Vanden Berghe, que muestra datos aparentemente reveladores: junto a escritores como Emmanuel Carballo, Juan Vicente Melo, Juan García Ponce y Huberto Batis, integrantes de la supuesta "mafia”, cuyas contribuciones a $L a$ Cultura en México de 1962 a 1972 alcanzan la "alarmante” cifra de 180 colaboraciones, hay más de 190 colaboradores que no llegan a publicar ni siquiera 10 artículos (1998: 130, 131). 
Todo lo tenían a su alcance: becas, espacios para publicaciones, pero, sobre todo, una capacidad y talento innegables de trabajo literario y cultural. Pereira, más adelante, apunta que un dato análogo podría sospecharse, a propósito de la presencia de determinados escritores en determinadas publicaciones, si pensamos en el Ateneo de la Juventud, en los Contemporáneos o en grupo denominado Taller, del que fueron partícipes Efraín Huerta y Octavio Paz.

En el escenario descrito a propósito de la llamada Generación de Medio Siglo y de la participación de José Emilio Pacheco en ella, cabe decir que su presencia se circunscribe a la beca del Centro Mexicano de Escritores, a sus publicaciones en la Revista Mexicana de Literatura, en el suplemento de Siempre! o en el de Novedades -por mencionar algunos- y a su única novela: Morirás lejos que, en efecto, comparte algunas de las ideas en torno a la escritura literaria que suscriben y ejecutan en sus obras narrativas, por ejemplo, Juan García Ponce. Juan Bruce-Novoa, en "Morirás lejos y la estética experimental de La Ruptura" (2004), señala los rasgos compositivos de la novela por la que se le "considera un ejemplo de participación mexicana en la novelística experimental internacional de la época, sobre todo asociada a la nueva novela francesa" (Bruce-Novoa 2004: 448). En esa línea se encuentran muchos de los relatos de Juan García Ponce, sostiene más adelante el mismo crítico (451). La experimentación narrativa, en el contexto de la obra de Pacheco, se detiene ahí, en Morirás lejos. El resto de sus relatos se adhieren, como lo ha señalado con suficiencia la crítica literaria, a los denominados “de iniciación” (Trejo 1994: 214), como lo es el caso de Las batallas en el desierto o alguno de los cuentos contenidos en El principio del placer o El viento distante, en los cuales descuella uno de los grandes temas de la obra de Pacheco: "La nostalgia por la niñez, propuesta como estado de inocencia e ingenuidad que devienen pureza, contrapuesta con la edad adulta, establecida ésta como ciclo vital conflictivo y emparentado con la noción de corrupción (en muchos órdenes, no sólo en el material) y decadencia” (214). Cabe agregar, a este rasgo de la otra narrativa de Pacheco, que la narración no es experimental, fragmentaria, como sucede en la novela. En este tenor, me permitiré decirlo, Morirás lejos es o el pico de pato o las patas de nutria del ornitorrinco.

Carlos Monsiváis y José Emilio Pacheco no sólo han coincidido a propósito de la beca del Centro Mexicano de Escritores; lo mismo sucede con los encuentros con Sergio Pitol. La amistad cultivada por los tres, por ejemplo, es descrita por el autor de El arte de la fuga en los siguientes términos: "José Emilio, Carlos y yo, caminamos por el Paseo de la Reforma, doblamos a la derecha en Niza hasta llegar a una taquería, al lado del cine Insurgentes, a donde pasamos con 
frecuencia por la noche a tomar caldos y a probar la más deliciosa variedad de tacos que uno pueda imaginar. Mientras comemos volvemos a hablar de literatura, y reiteramos nuestras preferencias” (Pitol 2014: 66).

Del archivo fotográfico del escritor Sergio Pitol, circuló y circula una fotografía (autoría de Ricardo Salazar, de 1959) donde aparecen, de derecha a izquierda, unos jovencísimos Carlos Monsiváis, Sergio Pitol y José Emilio Pacheco. La fotografía circuló en diversos medios de comunicación impresos y virtuales, luego de que los tres volvieran a reunirse con motivo de la celebración por el Premio Cervantes en 2009, y que Marcelo Uribe tomará una fotografía donde aparecen en el mismo orden los tres escritores, pero ahora sentados en un sofá; Pacheco lleva bastón, Pitol y Monsiváis lucen, ya, calvos.

De la Generación del Medio Siglo, Monsiváis, Ibargüengoitia y Pacheco cuentan con una copiosa producción periodística, particularmente de crónica. Pero incluso ese grupo al interior del grupo, muestra profundas diferencias en su escritura periodística. Los Inventarios de Pacheco están más cerca del centauro de los géneros que del ornitorrinco de la prosa; es decir, son, como se verá, más crítica literaria que crónica en el sentido en que la comprende el mismo Monsiváis: "la crónica mexicana verifica o consagra cambios y hábitos sociales y eleva lo cotidiano al rango de lo idiosincrático" (Monsiváis 2003: 35). Los Inventarios de Pacheco pocas, muy pocas veces, toman como centro de su escritura un tema cotidiano, pero, sin duda, lo hace. Volveré sobre este asunto más adelante. Por ahora, me interesa destacar la rareza ratificada este ornitorrinco llamado José Emilio Pacheco. Sus crónicas, incluso, son anómalas en el grupo al interior del grupo. Me permitiré exponer, sucintamente, un ejemplo. Si se observan, a vuelo de pájaro, los títulos de las crónicas de Monsiváis, el lector podrá advertir la pluralidad, la apabullante diversidad de temas que este escritor lleva a la mesa cuando escribe crónica. En Las esencias viajeras (2012): Simón Bolívar, el patriotismo, América, los conservadores, la censura, el Centro Histórico de la ciudad de México, las zonas conurbadas, Latinoamérica en el siglo XXI, José Joaquín Fernández de Lizardi, la mazonería, Juárez, Rubén Darío, José Enrique Rodó, la reforma universitaria de 1918, el humanismo en América Latina, Alfonso Reyes, Manuel González Prada, el costumbrismo, la Revolución mexicana, Pancho Villa, Emiliano Zapata, Lázaro Cárdenas, el cine, Hollywood, Guillermo Cabrera Infante, la Guerra Fría, el Ché, Cortázar, la globalización, entre muchísimos otros más.

En los Inventarios de José Emilio Pacheco, al menos en la tercera parte de ellos a los que tenemos acceso gracias a la antología de Héctor Manjarrez, Eduardo 
Antonio Parra, José Ramón Ruisánchez y Paloma Villegas, podemos advertir una constante: los asuntos literarios, así como temas históricos de profundo calado en la vida cotidiana, política, social o económica de México y de otros países.

Antes de ocuparme de la concepción poética que descuella en algunos momentos de los Inventarios, me permitiré apuntar esas crónicas en las que Pacheco convoca un elemento de la vida cotidiana, aunque no para elevarlo a nivel de idiosincrasia, como apunta Monsiváis. El empleo de los detalles, de lo singular, en las crónicas dedicadas a la máquina de escribir y al sándwich, por ejemplo, producen una reflexión que se despliega en esas páginas consagradas al periódico, pero que conecta a los Inventarios con el resto de la obra de Pacheco.

En el Tomo I, el texto titulado "La máquina de escribir (1878-1978)" del 18 de septiembre de 1978, está divido en cuatro apartados. Cada uno de ellos, lleva por subtítulo las letras que corresponden a cada fila de teclas tanto en la parte superior, media e inferior del teclado, esto es: "QWERTY", "POIU", "ASDFG” y "ZXCV". El texto es un recorrido por los nombres y las fechas que tienen injerencia en la creación, modificación y mejoramiento de esa máquina. Se trata de cien años a lo largo de los cuales se lanzó al mercado, en Nueva York, la máquina Remington modelo, que tenía "el grave defecto de escribir sólo mayúsculas” (I: 321). Fue hasta 1878, explica Pacheco, que se agregó un "simple resorte que permitió la impresión de minúsculas y mayúsculas” (I: 321). Y acá viene, como es regular en las crónicas de Pacheco, el tema literario. A propósito del ingreso de ese artefacto a nuestras vidas cotidianas, apunta:

La resistencia fue poderosísima: en países tan atrasados como el nuestro duró por lo menos hasta la década pasada [es decir, en la década de los sesenta]. En los noventa, veinte años después de que habían aparecido en Nueva York y en Londres las secretarias, un joven mexicano, Federico Gamboa, escribió un cuento escandalizado: “El primer caso” de una joven que es la primera que entra en un despacho y, “consecuentemente”, la primera que da a luz un hijo sin padre en una nueva maternidad (I: 322).

Pacheco se refiere a los primeros escritos de ficción del autor de Santa (1903), en donde narra cómo una jovencita es seducida por su jefe, en su primer trabajo, y resulta embarazada. El tema de la madre soltera, como se recordará, está presente en Las batallas en el desierto. Mariana, la madre de Jim, y de quien se enamora Carlitos, es una de las muchas mujeres que ingresaron a esa "nómina". En el resto de las páginas de la crónica sobre la máquina de escribir, Pacheco convocará a Max Aub, Henry James, Martín Luis Guzmán, Carlos Fuentes, Ezra 
Pound y al poeta peruano Sebastián Salazar Bondy. Es en el último subtítulo, "ZXCV”, en donde Pacheco articulará una suerte de reflexión poética que toma como pretexto los cien años de la máquina de escribir. Antes de comentarlo, no quiero dejar de mencionar que esa manera de llamar a los subtítulos, refieren a la pura materialidad del proceso de la escritura. Pareciera que cuando Pacheco tecleaba su columna, estaba, precisamente, mirando las teclas de su máquina. Esto permite aventurar que Pacheco además de no preguntarse cómo pasa el tiempo, sí que se pregunta qué pasa cuando se escribe, qué sucede entre el pensamiento y la herramienta que materializa ese pensamiento. Esta consideración encuentra una apoyatura en uno de los momentos que cierran la crónica: "Porque en última instancia la máquina de escribir es la herramienta que hace visible lo invisible, que da materialidad a las ideas encarnadas en las palabras. Es la casa de las palabras y todo su poder se encierra en un mínimo teclado" (I: 325).

En el parágrafo resuenan algunas de las ideas de Martín Heiddeger a propósito de la poesía. Quizá la relación más evidente la encontramos cuando Pacheco habla de la máquina de escribir como "la casa de las palabras" que, inevitablemente, convoca a la sentencia del filósofo alemán en la Carta sobre el humanismo: "el lenguaje es la casa del Ser. En la morada que ofrece el lenguaje habita el hombre. Los poetas y los pensadores son los guardianes de esta morada" (en Reale 2010: 525). La relación se enriquece si tenemos a la vista que, en opinión de Heidegger y particularmente en Hölderlin y la esencia de la poesía (1937), es el lenguaje de la poesía el que pone a la vista aquello que se oculta, es la poesía la que devela al Ser; Pacheco lo dirá de una manera menos robusta y compleja: "hace visible lo invisible". Y esto no es otra cosa que el reino de la poesía. En un poema de No me preguntes cómo pasa el tiempo, titulado "Mundo escondido":

\author{
Es el lugar de las computadoras \\ y de las ciencias infalibles. \\ Ante mis ojos te evaporas \\ -y creo en las cosas invisibles (2009 74).
}

En la máquina de escribir, en centenario, el autor de Tarde o temprano encuentra un pretexto para apuntalar ciertas reflexiones compactas o ajustadas, por así decir. Será en otros momentos de su obra en donde esa ceñida reflexión encuentre un despliegue y una conexión o resonancia con la poética de este ornitorrinco. Para finalizar el comentario a esta crónica dedicada a la máquina 
de escribir, no quiero dejar de señalar esa última afirmación de Pacheco sobre el teclado como el lugar, la casa, donde está concentrado todo el poder de las palabras. En el ASDFG o en el QWERTY se concentran infinitas posibilidades de escritura, el meollo es la combinación de las mismas para lograr, como le gustaba a Ramón López Velarde, encontrar el adjetivo categórico, rotundo. Como en toda poética, no es qué dice el poeta, sino cómo lo dice.

\section{Hablemos del sándwich}

La crónica dedicada al sándwich, y a su natural contracara, la torta, fue publicada el 19 de julio de 1999. Se trata del Inventario 1185 de Pacheco. El recorrido que hace sobre la invención y facetas de lo que se convertiría en fast food, un detalle de la vida cotidiana, le sirve al autor de Las batallas en el desierto para introducir algunas discusiones y problemáticas en torno a la usanza culinaria inglesa, norteamericana, francesa y, por supuesto, la mexicana. La mención a Salvador Novo no puede faltar, el autor de Cocina mexicana. Historia gastronómica de la Ciudad de México (1967), junto con la mención a Valle Arizpe y Carlos Monsiváis, apunta Pacheco, es menester porque ellos son autoridades en el tema del antojito. Los temas que trae a la mesa son nuevamente detalles, mediante los cuales no pretende poetizar o reflexionar sobre la poesía de manera ajustada y sintética, como se vio a propósito de la máquina de escribir. Los tópicos son muchas de las veces librescos o cercanos a la historia de México o del mundo. Sin embargo, no tiene empacho en convocar, por ejemplo, a la torta como la antípoda del sándwich, es decir, congrega elementos prosaicos o chabacanos, para reunirlos con lo refinado y delicado y, así, señalar deliberadamente una ironía. Sobre un libro de Raymond Sokolov, titulado Why Eat What We Eat, apunta la inmediata referencia al ensayo de Novo sobre la gastronomía y sobre el que descansa el libro del estadounidense, no sin antes señalar cómo el encuentro entre el Viejo Mundo y el Nuevo Mundo modificó de manera radical nuestra manera de alimentarnos: "Redentor, asesino o lo que sea, Colón es la figura más importante en la historia de la comida. Él puso en movimiento la migración transoceánica de ingredientes sin la cual, por ejemplo, los italianos no tendrían pizza ni los mexicanos tacos de carnitas” (III: 320). En los barcos españoles llegaron no sólo los evangelizadores o los conquistadores, llegaron el trigo y el olivo.

Pacheco resalta "otro encuentro invasor", a propósito de la comida: "El sándwich debe de haber llegado a México (si no lo trajo Poinsett que a cambio 
se llevó la flor de Nochebuena) con las tropas de Winfield Scott. No está documentado, pero es probable que se haya comido por primera vez en 1847, en el hotel y restaurante de la Bella Unión” (III: 320). Aquí descuella el dato histórico que sirvió de telón de fondo o de base para mucha de la narrativa mexicana del siglo XIX: la invasión norteamericana. El también autor de El viento distante puntualizará detalles de otra invasión culinaria, pero hacia mediados del siglo XX en la emblemática Las batallas en el desierto, donde aparece nuevamente la fast food. Del primer encuentro de Carlitos con Mariana, madre de Jim, el narrador Carlitos, apunta:

\footnotetext{
Pasen a merendar, dijo Mariana. Y nos sentamos. Yo frente a ella, mirándola. No sabía qué hacer: no probar bocado o devorarlo todo para halagarla. Si como, pensará que estoy hambriento; si no como, creerá que no me gusta lo que hizo. Mastica despacio, no hables con la boca llena. ¿De qué podemos conversar? Por fortuna Mariana rompe el silencio. ¿Qué te parecen? Les dice Flying Saucers: platos voladores, sándwiches asados en ese aparato. Me encantan, señora, nunca había comido nada tan delicioso. Pan Bimbo, jamón, queso Kraft, tocino, mantequilla, kétchup, mayonesa, mostaza. Eran todo lo contrario del pozole, la birria, las tostadas de pata, el chicharrón en salsa verde que hacía mi madre (2001 28, 29).
}

En la mesa de la casa de Mariana, se da una muestra del encuentro entre el american way of life y la vida en México durante el periodo presidencial de Miguel Alemán; se trata del México de los años cuarenta en el que ingresó intempestivamente no sólo la fast food, sino también que se modificaron otros órdenes de la vida cotidiana. Recuérdese que el padre de Carlitos es el dueño de una fábrica de jabón, que está a punto de quebrar por la inminente entrada del detergente el polvo al mercado mexicano o que el mismo personaje, como se nos narra en el apartado "Inglés obligatorio": "Acabada de aprobar, el primero en su grupo de adultos, un curso nocturno e intensivo de inglés y a diario practicaba con discos y manuales” (2001: 47). Las modificaciones de la vida cotidiana en el México de los años cuarenta, aparecen tanto en Las batallas... como en las crónicas de Salvador Novo que José Emilio Pacheco compiló y prologó en 1994 bajo el título La vida en México en el periodo presidencial de Miguel Alemán.

En la sucinta revisión y comentario a las crónicas dedicadas a la máquina de escribir y al sándwich, la temática histórica despunta invariablemente. Y no puede ser de otra manera si tenemos en cuenta que los tópicos relacionados con la memoria crítica, es crucial para un escritor como José Emilio Pacheco. El título que reúne toda su obra escrita en verso, Tarde o temprano, da cuenta de 
que, en efecto, el paso del tiempo, los implacables efectos de Cronos sobre el hombre y la realidad, son temáticas que afloran en todo su proyecto escritural. He apuntado memoria crítica, porque en Pacheco si algo prevalece es precisamente eso, la memoria crítica y no la nostalgia: "La nostalgia es la invención de un falso pasado. A ella se opone la mirada crítica. Estoy en contra de la idealización de lo vivido, pero totalmente a favor de la memoria” (Pacheco en Bravo 2009: 69).

El mismo trato le merece la literatura. Para José Emilio Pacheco la memoria crítica sobre la historiografía literaria es decisiva y no sólo en la escritura del verso o de la prosa, sino también en el ejercicio de la crítica literaria. El 31 de enero de 2018, publica en Letras libres el texto “Ovidio en el Ipod”. El artículo, en un tono análogo al de los Inventarios, problematiza el tema de la escritura de la poesía frente a las plataformas que el internet y la fibra óptica han socializado durante las últimas décadas; más todavía, pone sobre la mesa la consabida dificultad del género: un mínimo número de lectores: "A una lectura de poesía asisten, en el mejor de los casos, cien personas; a un concierto de rock, cien mil. De un libro de poemas se venden, durante varios años, si se logra el milagro de permanecer en circulación, mil ejemplares. De un disco, aún en la época en que es posible «bajarlo» de internet, un millón de copias” (2008). En el parágrafo XI, contrasta a la poesía con el futbol, y aclara: “[...] No dejo de pensar en lo que México sería si la gente supiera de poesía el uno por ciento de lo que sabe del futbol, su historia, sus técnicas, sus grandes figuras, su pasión, su misterio”. Ésa es, de manera muy sucinta, la manera en que José Emilio Pacheco concibe no sólo la lectura de la poesía, sino también la escritura de la misma. En el poema “D.H. Lawrence y los poetas muertos”, de Irás y no volverás (1969-1972):

\author{
They look on and help \\ No desconfiemos de los muertos \\ que prosiguen viviendo en nuestra sangre. \\ No somos ni mejores ni distintos: \\ tan sólo nombres y escenarios cambian. \\ Y cada vez que inicias un poema \\ convocas a los muertos. \\ Ellos te miran escribir, \\ te ayudan (Pacheco 2009: 151).
}

Ésta es una de las muchas formas en que Pacheco se refiere a la tradición literaria: los muertos. Su obra está plagada de esta concepción poética. En la 
edición de 1986 de Tarde o temprano, anota: "La poesía no es de nadie, se hace entre todos” (Tarde 246). Ésta es una de las máximas de Julián Hernández heterónimo de Pacheco- que antecede a las Aproximaciones o traducciones del poeta. Cabe decir que esta máxima proviene del dictum del Conde de Lautréamont: "La poésie doit être faite par tous" (1988: 590).

El epígrafe del poema que arriba he citado, además, permite establecer un lazo con otro de los poemas que Pacheco aproximó -como el autor llama a sus traducciones en la edición de 1986 de Tarde o temprano (10)- o tradujo de Malcolm Lowry: "Rilke y Yeats", particularmente con el primer verso del poema: “Ayúdenme a escribir”. El poeta y novelista inglés implora el abrigo de, ni más ni menos, dos de los poetas fundacionales de la tradición lírica de todos los tiempos. Ahora bien, la mención a Lowry, tan sólo por su país de origen, me permite introducir una de las problemáticas que, desde el punto de vista teórico y reflexivo, despuntan en dos de las crónicas contenidas en el tomo I de los Inventarios. Me refiero a "La otra vanguardia [I]" y "La otra vanguardia [II]", publicadas el 10 y el 17 de abril de 1978, respectivamente.

En los mencionados textos, Pacheco discurre sobre una corriente literaria "realista y no surrealista, [que] parte de la new poetry estadunidense. Su aparición es de tal manera subrepticia que ni sus propios introductores se dan cuenta de lo que han aportado" (I: 289). Los fundadores de "la otra vanguardia”, en opinión de Pacheco, son Pedro Henríquez Ureña, Salomón de la Selva y Salvador Novo. La senda a recorrer por las reflexiones y especulaciones ahí contenidas, permitirá advertir cuáles elementos componen la concepción poética de Pacheco, en esas dos crónicas en un primer momento, para después problematizar desde los linderos teóricos en qué consiste lo ajustada de su concepción. Como avanzada de lectura, apunto aquí que el ceñido pensamiento ahí contenido es de dicha naturaleza debido al género discursivo que aparentemente suscribe la crónica, pero dicha angostura obedece a otros designios que poco tienen que ver con la pertenencia al género discursivo.

Los Inventarios de Pacheco, como se verá, se aproximan al deber ser de la crónica literaria, pero dejan de pertenecer a ese género, es decir, se degeneran, para convertirse en una forma muy peculiar de crítica literaria que no es ni académica ni de divulgación. Como se verá, los elementos discursivos el deber ser crónica- van menguando en sus Inventarios, de tal suerte que en su aminoramiento dejan una filigrana, un rastro que permite reconocerlos como crónica, pero contaminada de otra cosa: verso, retrato, anécdota, chisme, etcétera. Es por ello que se postula la ajustada concepción, no por lo breve de los 
Inventarios, sino porque es mediante la borradura, el detrimento, que se busca llegar a ese estado nimio, casi imperceptible, casi de limo, que le permite ser otra cosa, siempre otra cosa, sin dejar de ser, al unísono, una crónica literaria.

\section{El influjo norteamericano}

Salvador Novo, el "cronista de la soledad” (I: 31), aparecerá en diversos momentos de los Inventarios de José Emilio Pacheco. La primera crónica, refiere la muerte del mismo, en 1974, así como los "pálidos honores" con que fue enterrado "el Cronista de la Ciudad y el Premio Nacional de Letras de 1967" (I: 31). El autor de Return Ticket y su obra serán temas de las crónicas de Pacheco, nuevamente, cuando en 1978 publiqué las ya aludidas “La otra vanguardia” I y II, textos que son discordantes en el contexto de los Inventarios, ya que su escritura y publicación no necesitó del pretexto fúnebre o del aniversario de publicación o de nacimiento y/o muerte de algún pensador, político, escritor o artista.

Las crónicas consagradas a apuntalar los elementos constitutivos de esa otra vanguardia, enuncian una serie de supuestos tanto teóricos como historiográficos de la literatura, particularmente de la poesía de la primera mitad del siglo XX. Agudo lector y crítico del modernismo, Pacheco intenta trazar las directrices de otro movimiento de cuño eminentemente americano, "al margen de la vanguardia de incitación europea” (I: 289). En suma, lo que Pacheco sostiene es la existencia de "otra vanguardia" que abreva de la new poetry estadounidense y que son Salomón de la Selva, Pedro Henríquez Ureña y Salvador Novo los artífices de la “expropiación” de la "dicción poética angloamericana” (I: 290), del "bilingüismo, afín al de Huidobro respecto del francés” (I: 293), del ejercicio "en las variedades de la versificación inglesa” (I: 294). De Salomón de la Selva, particularmente, Pacheco destaca que éste experimenta "una muerte masificada y tecnificada” (I: 293-294) de la Primera Guerra Mundial y esto tendrá como corolario la fundación de:

\footnotetext{
una poesía antiheróica en que lo primero que se desplaza es la representación del poeta mismo como hablante. A la máscara triunfalista del creacionismo o del estridentismo, al "mago", se opone el poeta como bufón y ser degradado. Escribir no es jugar al "pequeño dios" sino una debilidad y una vergüenza. Una manera de expiarla es bajar al reino de los suelos y describir lo que sucede a ras de tierra (I: 296).
}

Éstos son los breves, los ajustados momentos en que estos Inventarios del autor de Morirás lejos, apuntan a tópicos y temas de corte teórico, particularmente 
de la poesía. Las nociones de “dicción”, “versificación”, "bilingüismo”, o decir que el poeta es un "bufón y ser degradado", ponen en circulación toda una serie de consideraciones que pertenecen al reino de la disertación en torno a la literatura. No será ahí en donde Pacheco despliegue, discuta o problematice esos conceptos caros a la teoría, porque el registro discursivo de la crónica lo impele. Aquí tenemos, como apunté líneas arriba, una muestra de la degeneración del género crónica literaria. Sin embargo, el descarrío no llega a consumarse como una separación total de la crónica; se constituye, más bien, como una suerte de huella, como ese lodo o cieno que deja el río para continuar su cauce. Es en esta filigrana en donde se atisba la ajustada concepción poética que descuella en, al menos, estos dos Inventarios de Pacheco.

Sobre el decisivo papel de Salvador Novo en la "otra vanguardia”, Pacheco señala al menos cuatro momentos de la obra de Novo en donde se configura dicho movimiento: Espejo (1933), Continente vacío (1935), "la nota necrológica sobre Pedro Henríquez Ureña, publicada en 1946 y recogida en La vida en México en el periodo presidencial de Ávila Camacho (1965); la última es una entrevista de 1958 con Emmanuel Carballo, recopilada en Diecinueve protagonistas de la literatura mexicana del siglo XX (1965)” (I: 291). Estos materiales sirven a Pacheco para trazar las directrices de la "otra vanguardia" a la luz de algunos momentos de la obra de Novo. Respecto de Espejo y Continente vacío, apunta la intromisión de elementos de lo "yanqui", de lo estadounidense, tanto estructural como temáticamente. Sobre la nota necrológica y la entrevista con Carballo, Pacheco recrea la relación que Novo sostuvo tanto con los discípulos del dominicano, esto es, Cosío Villegas, Eduardo Villaseñor y Salomón de la Selva: "A este grupo, fundamentalmente interesado en las letras inglesas, se oponía en cierto modo el reunido en torno a Vasconcelos: Jaime Torres Bodet, José Gorostiza, Enrique González Rojo y Bernardo Ortiz de Montellano, es decir, el núcleo de los futuros Contemporáneos, más inclinados a la literatura francesa [...]” (I: 291).

En ese tenor, es fundamental, también, la intervención de Pedro Henríquez Ureña, quien "guio las lecturas y ejercicios literarios de Novo" (I: 291), en una directriz muy particular: la poética angloamericana. La cercanía del dominicano con las letras inglesas, apunta Pacheco en "La otra vanguardia II", se da acompasada con su conocimiento de la literatura española e hispanoamericana: “[...] en sus Ensayos críticos”, un libro de sus veintiún años, hay un comentario sobre De profundis de Wilde que acababa de publicarse en Inglaterra. Al año siguiente se ocupa de Edith Wharton en la Revista Moderna. Es, como bien se 
sabe, el aglutinador y maestro socrático de la generación mexicana de 1910, reunida en el Ateneo de la Juventud. Cuando llega a Estados Unidos conoce a Salomón de la Selva” (I: 293).

Tenemos así, que lo que urde Pacheco es una crítica literaria compuesta de una contextualización histórica, generacional, poética, en torno al asunto que le ocupa: verificar la "hipótesis de trabajo sobre esta «otra vanguardia»" (I: 290), como lo apunta en los primeros momentos del primer texto; acompañan a esta contextualización los breves momentos en que apenas atisba una reflexión en el marco de la teoría de la poesía, como se vio líneas arriba. El incipiente trabajo historiográfico -generacional, poético- tampoco puede o debe ser exhaustivo, porque, nuevamente, lo impele el género. Uno de los elementos que parecen recordarle que no puede desbocarse, o terminar de degenerarse, es, ni más ni menos, que uno de los elementos que distinguen a la crónica; es decir, fijar la fecha, el año, el motivo temporal por el que esa crónica ha sido escrita. En ese tenor, hay que recordar que ambas son publicadas en 1978, año que se menciona constantemente en ambos inventarios, pero no para convertirse en el centro en torno del cual girará el texto, sino para anclarlo, para dejar ese lodo o cieno del género crónica periodística. Apunta Pacheco: “[...] como aclaró en 1968 Roberto Fernández Retamar” (I: 289). Aquí, abre la posibilidad de pensar en esos inventarios como textos escritos a propósito de los diez años de la publicación de Cuba. Historia, La Habana; o cuando menciona el año de publicación de El joven de Novo, en 1928; o La cultura pocha en México de Julio de la Fuente en 1948; o como cuando hace un parangón entre el panorama derruido y atroz, de la guerra, en El soldado desconocido de Salomón de la Selva y dice: "El panorama que se observa es el arquetípico del siglo XX -Verdún 1917, Líbano 1978-” (I: 295), para aludir a la invasión de Israel al sur del Líbano en ese año.

\section{La ajustada concepción poética}

Debido, quizá, a la reciente publicación de la antología de los Inventarios, son pocos los acercamientos críticos agudos y profundos sobre el trabajo periodístico de Pacheco. De entre las reseñas a los libros y comentarios con motivo de la publicación de los mismos, algunos críticos parecen estar de acuerdo la singularidad de la columna. Pablo Sol, por ejemplo, apunta: "incluye la ficción, el ensayo y la crónica histórica, pero es, fundamentalmente crítica literaria. Quizá Pacheco haya sido el más lector de nuestros escritores desde Reyes, de cuya diversa curiosidad y buena prosa fue uno de los mejores herederos” (Sol 14). 
En el mismo tenor, escribe Sara Sefchovich: "De entre lo que se aprende con Pacheco en estos escritos destaca el cómo hacer crítica literaria, pues la suya es una propuesta de método, una propuesta de crítica que nada tiene que ver con los elogios ni con las injurias, sino que se sustenta sobre argumentos” (Sefchovich 2017: 51).

De ambas apreciaciones, cabe notar la coincidencia en señalar que las crónicas de Pacheco son crítica literaria, pero en un sentido muy lejano al que se cultiva hoy en las academias universitarias o institucionales. Su prosa periodística está en las antípodas del análisis de elementos formales o estéticos de la obra o del autor del que se ocupa, sin embargo, no tiene empacho en señalar alguno de los procedimientos retórico-estilísticos que, por ejemplo, emplea Ramón López Velarde en sus poemarios; lo suyo, tampoco se limita a señalar la coincidencia o discordancia del autor o de la obra con algún movimiento literario, por ejemplo, cuando habla del modernismo de Rubén Darío o de la “otra vanguardia”; en cuanto a contextualizar histórica-social y políticamente al autor o a la obra que le ocupan, Pacheco suele entresacar algún elemento significativo de dicho contexto para presentarlo a su lector como en una suerte de diorama, es decir, y por ejemplo, trae a cuento el Golpe de Estado en Chile de 1973, y lo coloca como telón para hablar de Pablo Neruda.

El breve espacio que se consagra a una crónica periodística no permitiría el desarrollo o problematización de un estado de la cuestión o de un marco de índole teórica, mucho menos permite poner en evidencia los resultados de un análisis o lectura profunda de un poema, por ejemplo, lo cual no significa que el cronista dispense ese trabajo, cuando se trata de hablar de literatura. Éste es el caso de las crónicas de José Emilio Pacheco. En los breves y ajustados momentos en que se atreve a poner en evidencia un pespunte de corte teórico o historiográfico de la literatura, lo hace como dejando una pincelada. Estas pinceladas son, como he apuntado, los momentos en que se advierte una manera de pensar o problematizar la literatura.

Tenemos así que los Inventarios, al menos los comentados y descritos aquí, participan tanto de la crónica como de la crítica literaria; en esa participación sin pertenencia cabal en alguno de los géneros discursivos, lo que ponen de realce es una suerte de contaminación, de mutación que impele constantemente a incorporarlos o congregarlos en un lado o en otro. En ese borramiento, ese dejar de ser crónica sin dejar de serlo, ese dejar de ser crítica literaria, sin dejar de serlo completamente, es donde, como se vio, asoma la ajustada concepción poética de José Emilio Pacheco. 


\section{Bibliografía}

BRAVO, H. (2009). "Nuevo elogio de la fugacidad. Una conversación con José Emilio Pacheco”. Letras libres 126: 67-71.

BRUCE-NOVOA, J. (2004). "Morirás lejos y la estética experimental de la ruptura”. La Torre, Revista de la Universidad de Puerto Rico 33: 447-468.

LAUTRÉAMONT. (1988). Obra completa. Trad. Manuel Álvarez Ortega. Barcelona: Akal.

MONTES, A. (2014). Políticas y estéticas de representación de la experiencia urbana en la crónica contemporánea. Buenos Aires: Corregidor.

MONSIVÁIS, C. (2012). Las esencias viajeras. Hacia una crónica cultural del Bicentenario de la Independencia. Pról. Antonio Saborit. México: Fondo de Cultura Económica.

MONSIVÁIS, C. (2003). A ustedes les consta. Antología de la crónica en México. México: Era.

NOGUEROL, F. (2009). “Introducción”. Contraelegía. José Emilio Pacheco. XVIII Premio Reina Sofía de Poesía Iberoamericana. Salamanca: Universidad de Salamanca.

PACHECO, J. E. (2018). “Ovidio en el Ipod”. Letras libres 109:26-29. <http:// www.letraslibres.com/mexico-espana/ovidio-en-el-ipod>. (Acceso 5 abril 2018).

PACHECO, J. E. (2017). Inventario. Volumen I. Selecs. Héctor Manjarrez, Eduardo Antonio Parra, José Ramón Ruisánchez y Paloma Villegas. México: Era/El Colegio Nacional/Universidad Autónoma de Sinaloa/ UNAM.

PACHECO, J. E. (2017). Inventario. Volumen II. Selecs. Héctor Manjarrez, Eduardo Antonio Parra, José Ramón Ruisánchez y Paloma Villegas. México: Era/El Colegio Nacional/Universidad Autónoma de Sinaloa/UNAM.

PACHECO, J. E. (2017). Inventario. Volumen III. Selecs. Héctor Manjarrez, Eduardo Antonio Parra, José Ramón Ruisánchez y Paloma Villegas. México: Era/El Colegio Nacional/Universidad Autónoma de Sinaloa/UNAM.

PACHECO, J. E. (2011). Las batallas en el desierto. México: Era.

PACHECO, J. E. (2009). Tarde o temprano (Poemas 1958-2009). Ed. de Ana Clavel. México: Fondo de Cultura Económica.

PACHECO, J. E. (1986). Tarde o temprano. (Los elementos de la noche, El reposo del fuego, No me preguntes cómo pasa el tiempo, Irás y no volverás, Islas a la deriva, Desde entonces y Aproximaciones). México: Fondo de Cultura Económica /Letras Mexicanas. 
PEREIRA, A. (1998). “La generación del Medio Siglo” en Juan García Ponce y la generación del Medio Siglo. (Colección Cuadernos). México: Universidad Veracruzana.

PITOL, S. (2014). El arte de la fuga. México: Era.

PONIATOWSKA, E. (1994). “José Emilio Pacheco: naufragio en el desierto”, en La hoguera y el viento. José Emilio Pacheco ante la crítica. (Sel. y prólogo Hugo J. Verani ). México: Era.

RAMOS, J. (2009). Desencuentros de la modernidad en América Latina. Literatura y política en el siglo XIX. Venezuela: El perro y la rana.

REALE, G. y ANTISERI, D. (2010). Historia del pensamiento filosófico y científico. III, del Romanticismo hasta hoy. Trad. Juan Andrés Iglesias. Barcelona: Herder.

REIG, R. (2006). Manual de literatura para caníbales. México: Random House Mondadori.

REYES, A. (1980). El deslinde. Apuntes para la teoría literaria. Obras completas. Tomo XV. México: Fondo de Cultura Económica.

SANZ, E. "El ornitorrinco es mamífero, ave y reptil, según su mapa genético". Muy interesante, 8 de mayo de 2008. <https://www.muyinteresante.es/ naturaleza/articulo/el-ornitorrinco-es-una-mezcla-de-ave-reptil-y-mamiferosegun-sus-genes $>$ (Acceso febrero 2018).

SEFCHOVICH, S. (2017). Vida y milagros de la crónica en México. México: Océano.

SOL, P. (2017). "Inventario. Antología/Los diarios de Emilio Renzi”. Criticismo 24: $14-17$.

TREJO, I. (1994). "La narrativa de José Emilio Pacheco: nostalgia por la infancia y la ciudad gozable”. La hoguera y el viento. José Emilio Pacheco ante la crítica. Sel. y prólogo Hugo J. Verani. México: Era.

VILLORO, J. (2005). Safari accidental. México: Joaquín Mortiz. 